\title{
Developing Affective Engagement in Science Education through Performative Pedagogies: The Performing Sciences
}

\author{
Sarah French $^{\mathrm{a}}$, Terrence D. Mulhern ${ }^{\mathrm{b}}$, Rinske Ginsberg ${ }^{\mathrm{c}}$ \\ Corresponding author: Sarah French (frenchs@unimelb.edu.au) \\ ${ }^{a}$ Melbourne Centre for the Study of Higher Education, University of Melbourne \\ ${ }^{\mathrm{b}}$ Department of Biochemistry and Molecular Biology, University of Melbourne \\ ${ }^{c}$ Victorian College of the Arts, University of Melbourne
}

Keywords: performance, affect, science education, higher education, teaching and learning

\begin{abstract}
The project The Performing Sciences engaged teaching staff from biomedical sciences and theatre to design an assessment activity in which second year students at the University of Melbourne were required to explicate a biochemical concept or process using embodied modes of performance. Here we provide an extended narrative on affective engagement, offering this previous work as a case study, and describing how this innovative work advances approaches to teaching, learning and assessment in science education through theatrical performance. The case study provides evidence of the potential for creative and multi-disciplinary forms of teaching, learning and assessment to foster student engagement and increase their motivation to learn science. Our extended narrative focusses on the potential for performance-based pedagogical approaches to facilitate affective forms of learning. We argue that by employing strategies from theatre and performance studies, science educators can engage students in emotional and corporeal ways that complement their cognitive processes, as well as facilitate opportunities for collaborative and social learning.
\end{abstract}

\section{Background and theoretical framework}

In recent years there has been a growing interest in the use of artistic teaching practices in science education. A range of science educators have observed that embedding artistic practices in the science curriculum can both improve student interest and assist students to better understand science (Gurnon, Voss-Andreae, \& Stanley, 2013; Izadi, 2017; Roy, 2017; Segarra et al., 2018; Turkka, Haatainen, \& Aksela, 2017). Artistic pedagogies also have the potential to develop students' transferable skills by encouraging students to view science through a creative lens, enhancing their abilities in areas such as public presentation, communication and teamwork, and fostering their skills in imaginative, critical and transdisciplinary thinking. Transdisciplinary and multidisciplinary approaches offer especially valuable pedagogical models as they help to better prepare students for the twenty-first century workplace, where broader transferable skills are increasingly viewed as vital graduate attributes that are as important as disciplinary-based knowledge (Miller \& White, 2013; Ruuskanen, Vehkamäki, Riuttanen, \& Lauri, 2018).

While teaching and learning in science can benefit from a range of artistic pedagogical approaches, we suggest that there are aspects of science education that especially lend themselves to the performing arts. Within our teaching context in undergraduate biochemistry and molecular biology, the concepts and processes that educators need to explicate include atomic level molecular characteristics such as reactivity, resonance and flexibility or higher order molecular and cellular features, such as enzyme catalysed reactions, receptor-binding, metabolic pathways and membrane transport. Theatrical performance, and especially 
performance modes that emphasise physical embodiment, offers a way to engage the imagination to illustrate these concepts and processes in dynamic and three-dimensional ways. Moreover, by facilitating embodied pedagogies, performance enhances the emotional and corporeal dimensions of student engagement, which has important implications for student learning, as we discuss below.

The use of performance is not especially common in university-level science education, however, there are some historical precedents. The most famous of these is the 1971 performance at Stanford University entitled Protein Synthesis: An Epic on the Cellular Level, a filmed performance 'happening,' with an introduction from Nobel prize winning chemist Paul Berg, in which students performed an embodied and organic interpretation of the biological process of protein synthesis. More recently, a range of science lecturers have documented their uses of drama and performance in the university classroom, including: the use of physical embodiment to teach students about the changing states of molecules (Metcalfe et al., 1984), the creation of 'molecular dramas' to explicate concepts in medical biochemistry (Reyes \& De Santos, 1984), the use of a scripted play to represent the biological processes that take place inside the body during physical exercise (De Paula, Da Costa, \& De Macedo, 1995), and dramatic role-plays in science and medical education designed to develop skills in areas such as communication and argumentation (Archila, 2017; Middlewick, Kettle, \& Wilson, 2012; Sloman \& Thompson, 2010), as well as to foster student engagement (Ünalan et al., 2009).

There are a considerable number of documented examples of the use of drama in science education at primary and secondary school levels (Darlington, 2010; Dorian, 2009; McSharry \& Jones, 2000; Smith, 2006; Warner, 2013), including a handbook by Abrahams and Braund (2012) that provides extensive practical instruction for secondary school teachers of chemistry, physics and biology. The authors present a strong argument for the effectiveness of using drama to teach science and provide descriptions of drama sessions that focus on the physical embodiment of scientific concepts, with the aim of promoting deep learning.

Performance-based teaching methods offer a form of embodied pedagogy, which has been shown to effectively integrate cognitive, corporeal, emotional and social forms of learning (McDonough, Forgaz, Berry, \& Taylor, 2016; Nguyen \& Larson, 2015; Macintyre Latta \& Buck, 2008). Nguyen and Larson (2015) describe embodied pedagogies as those which encourage learning "that joins body and mind in a physical and mental act of knowledge construction" (p.332). In contrast to traditional pedagogical approaches in science education that tend to separate mind and body, performance techniques promote an alignment of cognitive and corporeal processes. In our use of embodied performance to explicate biochemical processes, to be discussed shortly, students were required to use their minds and bodies simultaneously to physically depict abstract scientific concepts. The use of performance in the science classroom therefore creates opportunities for affective forms of learning, which we argue are important for student motivation and engagement. The following discussion examines the role of affect in the science curriculum, before turning to an analysis of our project The Performing Sciences, which demonstrates the potential for performance-based pedagogical approaches to facilitate affective forms of teaching and learning in science education.

\section{The 'affective turn': Implications for science education}

The 'affective turn' (Clough, 2007) that took place throughout the humanities and social sciences in the 2000s has given increased emphasis to emotions and bodily affects as objects of scholarly analysis and drawn attention to the interrelationship of psychic, social and embodied layers of experience. Affect theory has received little attention in science education, 
which tends to view pedagogy as a discursive practice that focuses predominantly on cognitive forms of learning. However, some recent scholarly writing by science educators shows a growing engagement with the role of affective pedagogies and suggests and that the discipline may have much to learn from the affective turn (Zembylas, 2014; 2016; Alsop, 2016; Keyumova \& Tippins, 2016).

The work of Zembylas $(2014 ; 2016)$ has been particularly instrumental in demonstrating the valuable contribution that affect theory can make to science education, and highlights both the affective social dimensions of teaching and learning, as well as the role of affects and emotions in university curricula. Zembylas acknowledges that such thinking challenges the epistemic boundaries of science, where emotion is often positioned as the 'other' to critical inquiry and rational scientific thinking. However, he argues that there are significant benefits to transcending traditional epistemologies and teaching practices in the sciences and to moving beyond the emotion/reason dichotomy that imposes limitations upon the discipline.

Following Zembylas and drawing upon the work of scholars of affect theory such as Ahmed (2004), this article defines affect in its broadest sense as a term that encompasses emotional responses, affective bodily reactions and interpersonal affective resonances. While many scholars of affect theory distinguish between emotion and affect (such as Masumi, 1995), connecting emotion to conscious and constructed processes and affect to pre-cognitive bodily reactions, such a dichotomy risks overlooking the ways in which corporeal, emotional, cognitive and social elements are intertwined within affective experiences. Indeed, in the teaching and learning context, these levels of experience are not easily separated.

In their discussion of the school teaching and learning context, Fredricks, Blumenfeld and Paris (2004) suggest that there are three interconnected psychological dimensions of student engagement: cognitive, behavioural and emotional. Cognitive engagement refers to intellectual thought processes where deep learning occurs with the activation of higher order thinking tasks such as analysis, synthesis and evaluation. At the behavioural level, engagement is promoted by active participation in teaching and learning activities as well as collaboration, interaction and active learning. Emotional engagement, for Fredricks et al., comprises positive and negative reactions that can influence students' willingness to work and therefore impact upon their motivation and persistence.

However, we suggest that by substituting the concept of emotion with affect, a broader understanding of the third level of student engagement emerges that incorporates emotions and feelings (towards teachers, peers, surroundings and course content), bodily experiences (voluntary and autonomic) as well as flows between bodies and social interactions. While students' individual emotional responses are likely to have an impact on their learning, an analysis of teaching and learning through the lens of affect theory shifts the focus from the psychological to the social and from the individual to the interpersonal. Sara Ahmed (2014) argues that "rather than seeing emotions as psychological dispositions we need to consider how they work, in concrete and particular ways, to mediate the relationship between the psychic and the social, and between the individual and the collective" (p.119). Ahmed emphasises that emotions are relational states, which has relevance to the classroom setting where interactive and collaborative learning tasks produce a shared learning experience within a social space, while also evoking a range of different and potentially conflicting individual emotional and affective responses.

Although this discussion privileges affective forms of teaching and learning, it is important to note that affect and emotion do not exist independent of cognitive and behavioural levels of 
engagement. The three levels are deeply interconnected and inform one another; for example, the experience of positive emotions and affects while learning can have an impact on student motivation and potentially deepen cognitive engagement. Similarly, participation in collaborative and interactive learning at the behavioural level might incite affective emotional responses. Our project The Performing Sciences employed techniques from theatre and performance studies to stimulate affective levels of student engagement and strengthen the relationship between cognitive, embodied and social forms of learning.

\section{The Performing Sciences: A case study in affective student engagement}

The Performing Sciences engaged teaching staff from biomedical sciences and theatre to design an assessment activity in which second year students at the University of Melbourne were required to explicate a biochemical concept or process using embodied modes of performance. The precursor for the project was a teacher-led pedagogical strategy that took place within lectures in the biochemical and molecular biology program in 2017, in which a teacherperformer embodied the side chains of the amino acids (Mulhern, 2017). We found that the process of physical embodiment provided a more tangible method for the lecturer to elaborate abstract concepts than two-dimensional textbook representations, and, anecdotally students reported that the performance helped them to understand the structure and function of the amino acids more effectively than didactic lectures or 'rote learning'. The lectures adopted an interactive format, allowing students to vote on which amino acid was being represented by the teacher-performer via an in-class polling tool. Students self-reported enhanced engagement in the lectures due to the fun and entertaining nature of the approach.

The amino acids lectures illustrated the potential for creative, performance-based pedagogies to assist in the teaching of complex scientific concepts, as well as to foster student enjoyment of learning science. However, we were interested in developing more active and interactive approaches to learning and teaching through a student-centred activity, and in employing performance techniques outside the lecture format where student collaboration is limited. The Performing Sciences was developed as a pilot study to assess the validity and effectiveness of using performance as a teaching and learning tool and as an assessment component in an undergraduate science course.

In the first semester of 2018 students undertaking the Bachelor of Biomedicine core $2^{\text {nd }}$ year subject Molecular and Cellular Biomedicine were given the option to participate in a physical performance-based assessment (The Performing Sciences). As part of the assessment activity, the students were supported by teaching staff from biomedical sciences and theatre to design and deliver a performance that explicated and elaborated a concept or process from the Biochemistry and Molecular Biology topic within the subject using a range of performance genres such as physical performance, performance art, mime, musical theatre and interpretive dance. The chosen topics were: glycolysis, adenosine triphosphate (ATP) synthesis, passive vs. active membrane transport, hydrophobic interactions, glucose transport, enzyme activity and protein folding. Titles of the performances included Glycolysis: The Musical (a song and dance act), The Enzyme Games (a game-show style performance with physical interaction) and ATP Synth-aces: Proton Power (a dance piece set to electronic music). A detailed description of the project is offered in Aston et al., (2018).

The task required the students to work collaboratively and communicate effectively to achieve the desired outcome, which was to illustrate their chosen biochemical concept or process as clearly as possible, as well as to entertain their peers. An in-depth understanding of the scientific content and ability to translate that content through physical embodiment was 
essential to the success of their performance. Equally, the students' theatrical choices such as the performance genre, use of text and music, physicality and gesture, and design of the miseen-scène, were all important elements and the students received training on aspects such as vocal projection and body language as they devised their performances. Such aspects, which are not usually part of a science curriculum, helped the students to acquire skills in communication and presentation, skills that are likely to be relevant to their future careers.

In addition to the goals relating to student learning, the project aimed to increase social connections amongst students and to promote student engagement and inclusion. The 42 students who participated in the activity were a diverse group and included a significant proportion of international students with different cultural backgrounds and different levels of English proficiency. With its emphasis on embodied pedagogies, as opposed to language-based forms of teaching and learning, The Performing Sciences project engaged with the principles of inclusive curriculum design, which promotes success among all students and allows students from different backgrounds to learn from one another (Morgan \& Houghton, 2011). The activity encouraged students to share and showcase their individual skills and talents, e.g. ballet, contemporary dance, singing and comedy, which enhanced their confidence and enjoyment of the task.

Performance-based pedagogies are especially effective in creating an inclusive teaching environment because they involve activities designed to put students at ease so that they can feel comfortable sharing ideas and working together in a non-judgemental space. For example, in the initial workshop, performance-based activities included moving physically within a large circle (Figure 1). Without using language, the students were instructed to employ movements under the conceptual umbrella of 'giving' and 'receiving' in which they used rhythmic physical gestures that built in intensity and shifted from generic to individualised expressions. In another 'hand shaking' exercise, students experienced touch and eye contact with one another prior to introducing themselves verbally, which encouraged them to bridge personal space, make an offering of themselves without resorting to language, and become attentive to being present in the space with others. Such activities, familiar to theatre and performance teachers, but most likely foreign to university educators outside of these fields, can play a key role in promoting affective forms of engagement on both individual and collective levels. Performance-based activities put the body first; rather than prioritising verbal communication, they focus on the language of the body, as well as the connections between bodies.

This emphasis on the body in the classroom setting, and on activities that facilitate play and creativity, have value in themselves, especially in promoting connections and communications between students, but we suggest that they also have a role to play in student learning. In the initial workshop of The Performing Sciences, the performance exercises that the students experienced in the first two hours allowed them to gain an understanding of how the body conveys meaning, and equipped them with basic skills in improvisation and spatial composition, that enabled them to begin to conceptualise ways to communicate scientific concepts in an embodied manner. When, in the final hour of the first workshop, students formed groups and began to conceive ideas for their assessment tasks, we observed that the links between the biochemical concepts and processes they had been learning about in their lectures and the ways that these might be embodied and performed were formed quite quickly. 


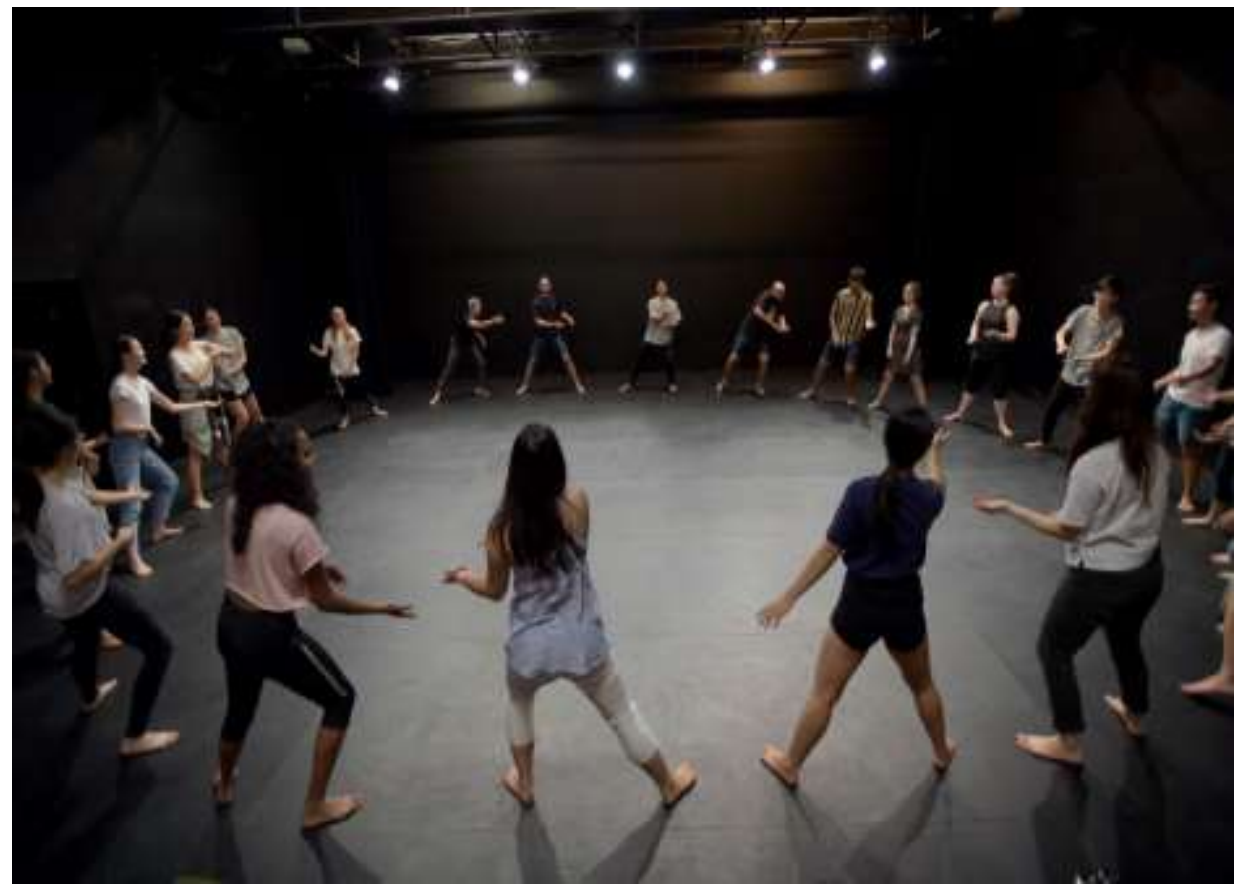

\section{Figure 1: Students engaging in performance-based exercises}

In the second workshop, performance activities were again employed as warm-up exercises for a much shorter duration, and then the students worked on devising and developing their performances with regular feedback from both a theatre teacher and their subject lecturer (Figure 2). The enthusiasm of the lecturers and their modelling of how to articulate complex ideas through physical embodiment were fundamental to the success of the project, as was the use of team-teaching in the curriculum design, with a combination of teaching staff with expertise in science and performance.

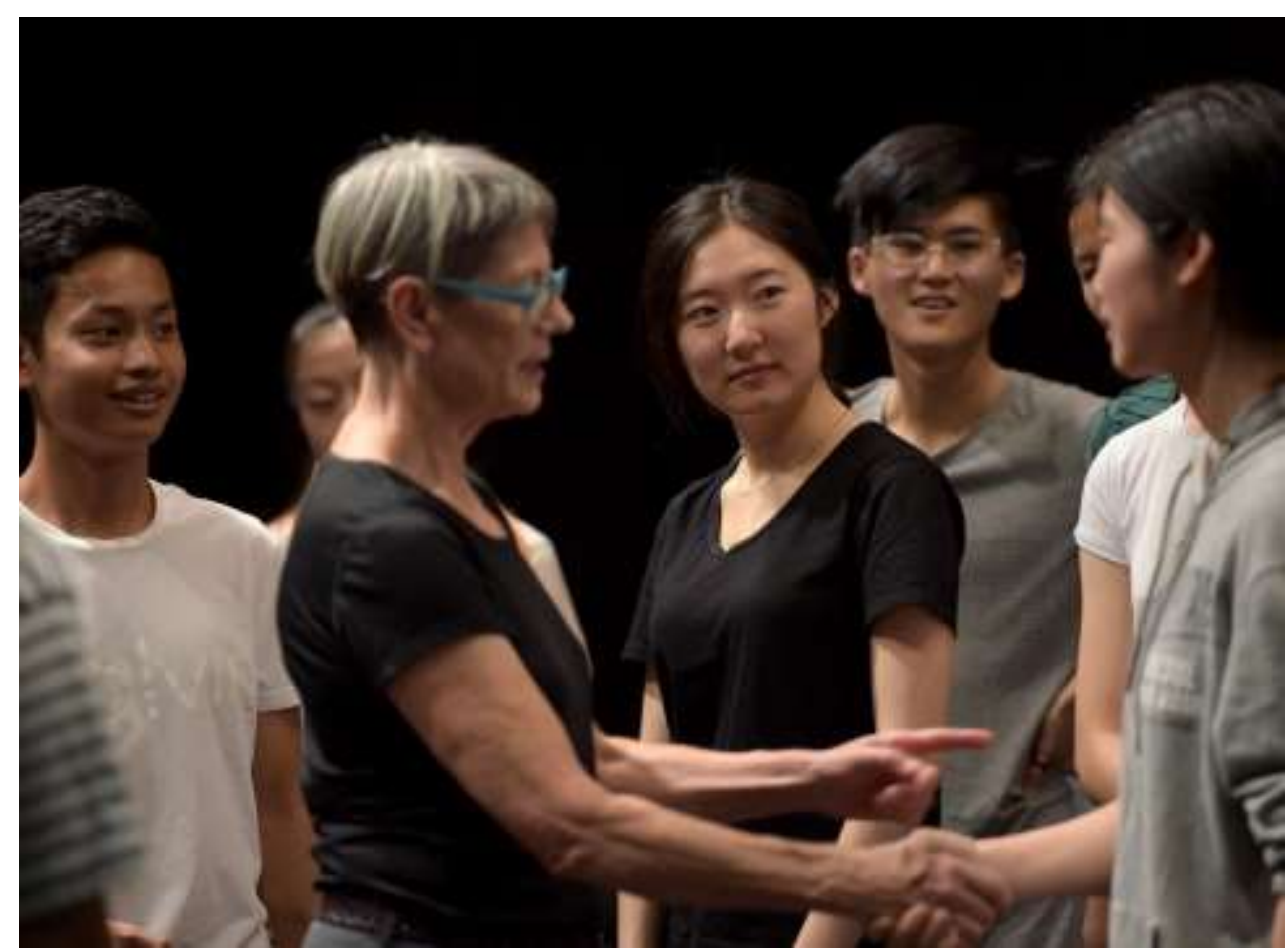

Figure 2: Students in rehearsal with theatre teacher Rinske Ginsberg 


\section{Summary findings from Case Study: The Performing Sciences}

To assess the benefits to students, data was collected via a student experience reflection survey, which was completed by 30 students. The survey included both quantitative components and qualitative open-ended questions. In line with the intended learning outcomes and project aims, the survey sought to assess the impact of The Performing Sciences on students' confidence in presenting, engagement with the subject, development of a range of transferable skills, and enhanced understanding of the subject content.

In our previous work (Aston et al., 2018), we analysed the data gathered through the student experience reflection survey to illustrate the value of the project in fostering student motivation and skills development. Extending upon this work, below we provide a more detailed examination of the project that highlights the ways in which The Performing Sciences facilitated embodied pedagogies and affective forms of learning. This discussion offers the project as a case study for advancing innovative approaches to science education while pointing to the broader implications of developing affective dimensions in the classroom in emotional, embodied and interpersonal ways.

Throughout the performance rehearsals we observed that the students appeared highly motivated, and there were noticeable levels of enjoyment in undertaking the activity. Students self-reported that they felt more engaged with the subject having participated in The Performing Sciences (Aston et al., 2018). Psychologists working in the field of higher education argue that such positive emotional experiences in the university setting are not only an important factor in student engagement and retention but are also crucial for effective learning. Pekrun and Stephens (2010), for example, contend that positive emotions are "instrumental for college achievement and personal growth" and that "experiencing enjoyment while working on a challenging project can help a student envision goals, promote creative and flexible problem solving, and support self-regulation" (p. 257, italics in original).

Emotional and affective responses were developed through the embodied nature of the activity, as well as through the opportunity to interact with other students in small groups. In large undergraduate degrees, especially in the science, technology, engineering and mathematics disciplines, such opportunities for collaborative learning experiences can be rare, yet they are crucial for improving students' sense of connectedness to their peers, their studies and the institution, and can play a central role in reducing attrition. As Tinto has argued, a sense of belonging is a key dimension of student motivation and persistence that universities can foster, in part by 'promoting those forms of activity that require shared academic and social experiences' (2017, p.4). A recent study found an increase in Australian university students reporting that they have not made at least one or two close friends on campus over a 5-year period (Baik, et al., 2015), suggesting that more cohort experiences may need to be integrated into university curricula. The Performing Sciences provided such an opportunity for collaborative and social learning. In the open-ended responses to the experience reflection survey, many of the students reported that working with their peers and making friends was one of the key benefits of being involved in the activity (Aston et al., 2018). 


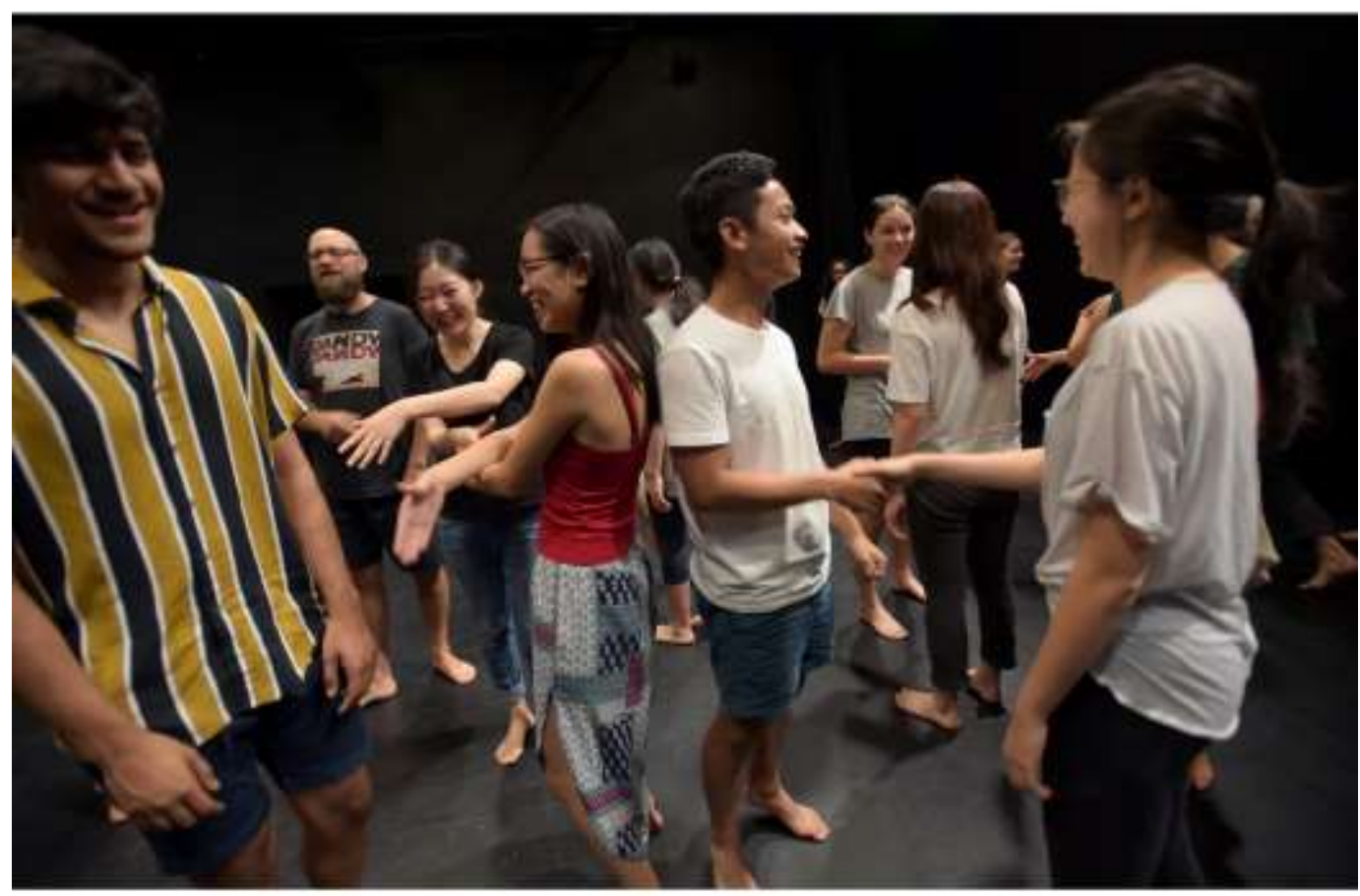

Figure 3: Students during the performance workshops

The curriculum and assessment design of the project aimed to capitalise on the benefits of peerlearning, and included, as part of the assessment activity, a peer-to-peer feedback task. Following the dress rehearsal, the students were provided with guidelines on how to effectively give and receive critical feedback and were required to provide anonymous feedback to the other performance groups, using specified assessment criteria. The feedback was moderated and delivered online to the students so that they could incorporate it into their final performances. This process of giving and receiving feedback was rated as very helpful $(100 \%$ broad agreement) in the experience reflection survey (Ashton et al., 2018) and students commented that the feedback process helped them to improve their own performances as well as to consolidate their understanding of their peers' work.

As our previous work suggested, in addition to the possible learning gains that stemmed from positive emotional engagement, the students also appeared to experience a form of kinaesthetic or corporeal learning (Aston et al., 2018) This highlights for us the important role of bodily affects in teaching and learning. Participants of The Performing Sciences perceived a correlation between the activity of physically embodying scientific concepts and an enhanced understanding of those concepts, with all students agreeing or strongly agreeing that they understood both topic of both their performances and the topics of the other performances after the activity (Aston et al., 2018).

Qualitative analysis of the open-ended survey responses suggested that the activity promoted deep-learning; for example, one student stated: "we had to research some aspects in depth to portray them with our bodies and theatrically, this made us really understand the concept in order to perform it". For this student, the use of performance as an embodied pedagogy was directly related to cognitive learning gains. For others, devising the performance helped them to consolidate their knowledge through discussions with peers and offered a helpful visual representation to assist in the understanding of the processes and concepts. It is also possible that the methodological approach of expressing ideas physically will impact upon their future 
learning; as one student commented: 'I can now imagine performing all the processes we study".

Students were asked to provide open-ended responses outlining which specific skills they felt they had learned by participating in The Performing Sciences. Following coding and thematic analysis, we found that the most common responses were: teamwork, learning how to communicate with the body, gains in confidence, skills in creative and/or artistic expression and skills in communication (Aston et al., 2018). It is notable that the skills identified by the students are all related to the affective dimensions of student engagement, as well as to the development of transferable skills.

While the performances that the students produced drew upon a range of theatrical styles and genres, they were encouraged to focus on the role of the body. This allowed us to explore the possibilities of embodied pedagogies and led to the creation of performances that might be described as affective in nature. For example, in one of the most striking performances entitled The Chaperone, the process of protein folding was depicted through a ballet set at a black-tie event in a ballroom. In this performance the chaperone is conceived as a 'gatekeeper' character who overseas and permits the amino acids to join the polypeptide chain (the ballet dancers), whilst blocking the lipid and sugar who try to bind with the hydrophobic element on the chain (the first dancer.) These disruptive elements employ alternative dance modes, unsettling the harmony of the ballet, but they are ultimately rejected for failing to meet the criteria of both the dance and the protein folding process. Once the synthesis of the amino acid chain is complete the chaperone is dispensed with and the group of dancers become autonomous. According to the properties of the amino acids and the molecular interactions, the independent polypeptide chain then folds into its conformational shape. The dancers sigh and lower their bodies to represent a lower energy state and to signify the completion of the folded functional protein.



Figure 4: Students performing protein folding in The Chaperone 
The Chaperone eliminated verbal language altogether to focus on communicating the concepts purely through bodily movements and through the interconnections and intensities between bodies. The process of protein folding is realised through a narrative that operates on multiple levels (performative, social and scientific) and through an engaging and affective theatrical depiction. In such examples, the assessment activity effectively realised the intent of The Performing Sciences to simultaneously develop the students' understanding of the scientific concepts and to enable them to meaningfully and creatively communicate those concepts using their skills in presentation, performance, collaboration and teamwork.

\section{Implications and limitations}

The Performing Sciences has the potential to be employed across a broad range of subjects to develop transferable skills and student engagement, as well as facilitate learning of subject content. Following internal presentations of our pilot study, teaching staff at The University of Melbourne have expressed interest in employing similar performance-based activities and assessments in Science Communication, Veterinary and Agricultural Sciences and Engineering. As in biochemistry, in each of these disciplines, key concepts and processes could potentially be explicated through embodied modes of performance.

However, there are limits to the scalability of the activity as it is employed in a teachingintensive format that requires relatively substantial contact hours to allow the students time to learn and develop skills in performance and to devise the group pieces. The 42 places offered for the pilot study was found to be an appropriate number for high-quality interaction in the rehearsal and performance setting. It would therefore be necessary to increase the number of classes if additional participants were to be included. The optional nature of the activity is also likely to have been important to student engagement and enjoyment as students with a genuine interest in performance were able to self-select to participate. Although student interest was higher than we had anticipated, with 90 students from a class of 520 initially registering to participate, we are cognisant that the activity will not appeal to all science students.

Another possible limitation to employing The Performing Sciences at other institutions relates to the need for involvement of multiple teaching staff from both science and theatre, which inevitably increases the costs of teaching, and raises the question as to whether science departments would have the expertise in the performing arts necessary for the effective teaching of the activity. Although it might be possible for science academics to facilitate aspects of performance practice within their classes, it is unlikely that these educators will possess high-level skills in teaching performance. Our pilot study found that engaging an experienced theatre teacher was vital to the success of the activity.

\section{Conclusion}

This article has argued that teaching strategies from theatre and performance studies offer science educators a way to expand their pedagogical approaches to create possibilities for affective learning. The Performing Sciences illustrates that embodied modes of performance can produce heightened affects in the classroom across the different affective dimensions including emotional, corporeal and interpersonal. These affective levels of engagement are rarely privileged within discussions of science education, or indeed within educational literature more broadly, yet they play a crucial role in students' interest and motivation towards learning and have the potential to either impede or advance the learning process.

We have also argued that affective engagement intersects with the other dimensions of student engagement and might have broader implications for student learning. The Performing 
Sciences demonstrates the capacity for embodied pedagogies to assist students to understand and retain concepts from the curriculum. It also highlights the potential for artistic and performance-based approaches to science education to engage students' imagination and creativity and increase their motivation to learn science.

\section{Acknowledgements}

This project was supported by Faculty of Medicine Dentistry and Health Sciences (MDHS) Learning and Teaching Initiative Seed Funding and The MDHS Award for Learning and Teaching Achievement. This project was approved by the University of Melbourne Biomedical Sciences Human Ethics Advisory Group (1851159.1).

\section{References}

Abrahams, I., \& Braund, M. (Eds.). (2012). Performing Science: Teaching chemistry, physics and biology through drama. London: Continuum.

Ahmed, S. (2004). Affective economies. Social Text, 22 (2), 117-139.

Alsop, S. (2016). Encountering science education's capacity to affect and be affected. Cultural Studies of Science Education, 11, 551-565.

Archila, P. A. (2017). Using drama to promote argumentation in science education. Science \& Education, 26, 345-375.

Aston, R., Mulhern, T.D., Ginsberg, R., \& French, S. (2018). 'The Performing Sciences'. Proceedings of the Australian Conference on Science and Mathematics Education (2018), 115-122.

Baik, C., Naylor, R., \& Arkoudis, S. (2015) The first year experience in Australian universities: Findings from two decades, 1994-2014. Melbourne: Centre for the Study of Higher Education, the University of Melbourne.

Clough, P. (Ed.). (2007). The affective turn: Theorizing the social. Durham: Duke University Press.

Darlington, H. (2010). Teaching secondary school science through drama. School Science Review, 91 (337), 109-113.

De Paula, E., Da Costa, C., \& De Macedo, D. (1995). Drama: A novel evaluation Tool Biochemical Education, $23(3), 133-135$.

Dorion, K. R. (2009). Science through drama: A multiple case exploration of the characteristics of drama activities used in secondary science lessons. International Journal of Science Education, 31 (16), 22472270.

Fredricks, J.A., Blumenfeld, P.C., \& Paris, A.H. (2004). School engagement: Potential of the concept, state of the evidence. Review of Educational Research, 74 (1), 59-109.

Gurnon, D., Voss-Andreae, J., \& Stanley, J. (2013). Integrating art and science in undergraduate education. PLoS Biology, 11(2), e1001491.

Izadi, D. (2017). Arts in science education. Canadian Journal of Physics, 95(7), xliii-xlvi.

Keyumova, S., \& Tippins, D. (2016). Toward re-thinking science education in terms of affective practices: Reflections from the field. Cultural Studies of Science Education, 11, 567-575.

Macintyre Latta, M., \& Buck, G. (2008). Enfleshing embodiment: 'Falling into trust' with the body's role in teaching and learning. Educational Philosophy and Theory, 40 (2), 315-329.

Massumi, B. (1995). The autonomy of affect. Cultural Critique, 31, 83-109.

McDonough, S., Forgaz, R., Berry, A., \& Taylor, M. (2016). All brain and still no body: Moving towards a pedagogy of embodiment in teacher education. In D. Garbett \& A. Ovens (Eds.), Enacting self-study as methodology for professional inquiry. (pp.433 - 439). Herstmonceux, UK: S-STEP.

McSharry, G., \& Jones, S. (2000). Role-play in science teaching and learning. School Science Review, 82 (298), 73-82.

Metcalfe, R. J., Abbot, S., Bray, P., Exley, J., \& Wisnia, D. (1984). Teaching science through drama: An empirical investigation. Research in Science \& Technological Education, 2(1), 77-81.

Middlewick, Y., Kettle, T.J., \& Wilson, J.J. (2012). Curtains up! Using forum theatre to rehearse the art of communication in healthcare education. Nurse Education in Practice, 12, 139-142.

Miller, B., \& White, F. (2013). Why arts and science are better together. The Conversation, June 25.

Morgan, H., \& Houghton, A. (2011). Inclusive curriculum design in higher education: Considerations for effective practice across and within subject areas. Higher Education Academy, York, UK. Accessed 16 January 2019, https://www.heacademy.ac.uk/system/files/resources/introduction_and overview.pdf

Mulhern, T. (2017). Physical biochemistry, but not as you've ever seen it before... Australian Biochemist 48 (2), 9. 
Nguyen, D.J., \& Larson, J.B. (2015). Don't forget about the body: Exploring the curricular possibilities of embodied pedagogy. Innovations in Higher Education, 40, 331-344.

Pekrun, R., \& Stephens, E.J. (2010). Achievement emotions in higher education. In J.C. Smart (Ed.), Higher Education: Handbook of Theory and Research. (pp. 257 - 306). Dordrecht, Netherlands: Springer.

Reyes, M.V., \& De Santos, M.V.R. (1985). Molecular drama in biomedical education. Biomedical Education, $13(1), 11-13$.

Roy, D. (2017). Integrating arts and science in the classroom. Teacher Magazine, 23 October.

Ruuskanen, T., Vehkamäki, H., Riuttanen, L., \& Lauri, A. (2018). An exploratory study of the learning of transferable skills in a research-oriented intensive course in atmospheric sciences. Sustainability, 10 (5), 1385.

Segarra, V.A., Natalizio, B., Falkenberg, C.V., Pulford, S., \& Holmes, R. M. (2018). STEAM: Using the arts to train well-rounded and creative scientists. Journal of Microbiology \& Biology Education 19 (1), 1-7.

Sloman, K., \& Thompson, R. (2010). An example of large group drama and cross-year peer assessment for teaching science in higher education. International Journal of Science Education, 32 (14), 1877-1893.

Smith, A. (2006). Science drama is for everyone. Teaching Science, 52 (1), 36-38.

Tinto, V. (2017). Reflections on student persistence. Student Success, 8(2), 1-8.

Turkka, J., Haatainen, O., \& Aksela, M. (2017). Integrating art into science education: A survey of science teachers' practices. International Journal of Science Education, 39 (10). 1403-1419

Ünalan, P.C., Uzuner, A., Çifçili, S., Akman, M., Hancioğlu, S., \& Thulesius, H. O. (2009). Using theatre in education in a traditional lecture oriented medical curriculum. MBC Medical Education, 9 (73).

Warner, C. (2013). Drama and science: An unlikely partnership for inquiry. In M. Anderson \& J. Dunn (Eds.), How drama activates learning: contemporary research and practice. London \& New York: Bloomsbury Academic.

Zembylas, M. (2014). Theorizing 'difficult knowledge' in the aftermath of the 'affective turn': Implications for curriculum and pedagogy in handling traumatic representations. Curriculum Inquiry, 44 (3), 390-412.

Zembylas, M. (2016). Making sense of the complex entanglement between emotion and pedagogy: Contributions of the affective turn. Cultural Studies of Science Education, 11, 539-550. 